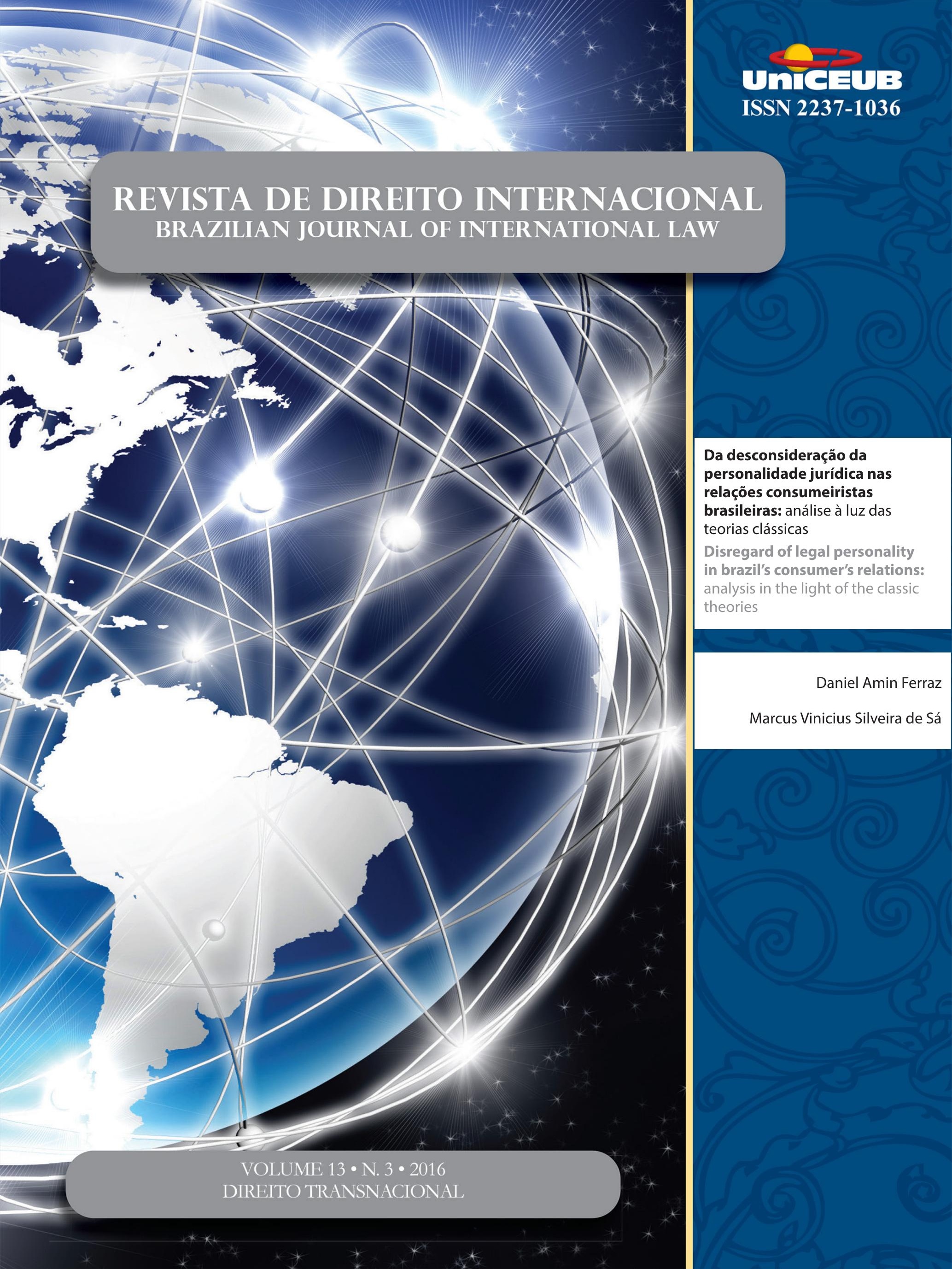


Crônicas da ATUALIdAde do direito internacional .................................................. 2

I. Dossiê Temático: Direito Transnacional .........................................................15

EDITORIAL: O Direito Transnacional - Circulação de normas e relações jurídicas transnacionais .......16 Priscila Pereira de Andrade

A emergênCia do direito transnacional ambiental .............................................18 Priscila Pereira de Andrade

Desafíos y RESPUESTAS TRANSNACIONALES FRENTE A LOS CRÍMENES AMBIENTALES ...............30 Rosmerlin Estupiñan-Silva

DiREITO TRANSNACIONAL E MUdANÇAS CLIMÁTICAS .50 Géraud de Lassus Saint-Geniès

Especies en movimiento: la Convención sobre el Comercio Internacional de Especies Amenazadas de Fauna y Flora Silvestres como espacio de “Encuentro” de discursos, ACTORES Y ESTRATEGIAS EN EL DERECHO AMBIENTAL TRASNACIONAL

María Valeria Berros e Dabel Leandro Franco

El carácter transnacional del Sistema comunitario de ECogestion « Eco-ManageMENT AND Audit SCHEME » (EMAS) DENTRo de LA UE y MÁs ALlÁ DE SUS Fronteras ......72 Adélie Pomade

O CONCEITO DE CONDUTA EMPRESARIAL RESPONSÁVEL À LUZ DOS ORDENAMENTOS JURÍDICOS BRASILEIRO, INTERNACIONAL E TRANSNACIONAL

Gabriel Webber Ziero

ARBITRAGEM NO DIREITO TRIBUTÁRIO INTERNACIONAL E NO DIREITO INTERNACIONAL DOS INVESTIMENTOS: UMA MANIFESTAÇÃO DO DIREITO TRANSNACIONAL

Vivian Daniele Rocha Gabriel 
O DIREITO TRIBUTÁRIO SOB UMA PERSPECTIVA TRANSNACIONAL

Franciele de Simas Estrela Borges

As Características do Direito Transnacional como Metodologia: Análise sob o enfoQue dos Aspectos Processuais da Arbitragem 126

Flávia Foz Mange

O DIREITO TRANSNACIONAL (“GLOBAL LAW") E A CRISE DE PARADIGMA DO ESTADO-CENTRISMO: É POSSÍVEL CONCEBER UMA ORDEM JURÍDICA TRANSNACIONAL? ...................................... 146

Luiza Nogueira Barbosa e Valesca Raizer Borges Moschen

TransPorte AÉREO E DIREITO TRANSNACIONAL: DA CONVERGÊNCIA À UNIFORMIDADE 160 Mickael R. Viglino

Outros Artigos. 175

O Fundo Monetário Internacional e a proteção dos direitos humanos: uma análise DO PROGRAMA DE CRESCIMENTO E REDUÇÃO DA POBREZA NO HAITI 177

Pablo Henrique Hubner de Lanna Costa e Carlos Alberto Simões de Tomaz

Um estranho no ninho? Padrões privados no Acordo de Barreiras Técnicas ao CoMÉRCIO DA OMC 192

Michelle Ratton Sanchez Badin e Marina Yoshimi Takitani

Os benefícios tributários do programa Inovar-Auto e os princípios da Nação Mais Favorecida e do Tratamento Nacional: uma análise dos argumentos dos Painéis atualmente em Curso contra o Brasil no Órgão de SoluÇão de Controvérsias da OMC . 211 Eric Moraes Castro e Silva

A ERA DA HUMANIDADE: REFLEXões PARA A HISTÓRIA DO DIREITO INTERNACIONAL 236 Henrique Weil Afonso

Precedentes vinculantes nos Estados Unidos da América e no direito brasileiro: Um ESTUDO COMPARADO 264

Patrícia Perrone Campos Mello 
IL DIRITTO AMBIENTALE SECONDO L'OTTICA DEL DIRITTO COSTITUZIONALE POSITIVO E LA RESPONSABILITÀ PER DANNI ALL'AMBIENTE NEL DIRITTO COMUNITARIO: LO STATO DELL'ARTE DEL DIRITTO AMBIENTALE COSTITUZIONALE E COMUNITARIO 287

Elcio Nacur Rezende

DA DESCONSIDERAÇÃo DA PERSONALIDADE JURÍDICA NAS RELAÇÕES CONSUMEIRISTAS BRASILEIRAS: ANÁLISE À LUZ DAS TEORIAS CLÁSSICAS

Daniel Amin Ferraz e Marcus Vinicius Silveira de Sá

ANALYSIS OF ADVANTAGES AND DISADVANTAGES OF FORUMS PRESCRIBED UNDER THE UNCLOS AND STATE PRACTICE: THE WAY AHEAD FOR INDIA ......................................................319

Vinai Kumar Singh

Do governo POR LEIS À governanÇA POR NúMERos: breve anÁlise do Trade in SERVICE AgreEMENT (TISA) ...............................................................................338 Jânia Maria Lopes Saldanha, Rafaela da Cruz Mello e Têmis Limberger

As DIRETIVAS EUROPEIAS COMO NORMA REGULADORA DO DIREITO ADMINISTRATIVO GLOBAL ..356 Alice Rocha da Silva e Ruth Maria Pereira dos Santos

O desenVolvimento da POlítica AGRícola COMUM dA UNião EUROPEIA 375 Tatiana de A. F. R. Cardoso Squeff

A imunidade de Jurisdição das organizaÇões internacionais FaCE AO Direito de aCESSO À JUSTIÇA 391

Fernanda Araújo Kallás e Caetano

O DIREITO INTERNACIONAL ENTRE O DEVER ÉTICO E A AÇÃo POLÍ́TICA: OS FUNDAMENTOS DE UM DEVER DE COOPERAÇÃO INTERNACIONAL NA FILOSOFIA POLÍTICA DE IMMANUEL KANT .405 Ademar Junior Pozzatti

EXTENSÃo E FRAGMENTAÇÃo NO CONTEXTO DA JURISDIÇÃO PENAL INTERNACIONAL .423 Marcus Vinícius Xavier de Oliveira

A DEFINiÇÃo JURÍdiCA DA "COMUNIDADE" .444 Nitish Monebhurrun, Michelle Lucas Cardoso Balbino, Fernanda Castelo Branco Araujo, Othon Pantoja, Míara Bogo Bruno e Cândida Dettenborn Nóbrega 
Comparative Study on Chinese Local Legislation of Science and Technology ProGRESS

LI Xiaoming e LI Yihan

O CONTROLE PENAL DO TRÁFICO DE PESSOAS: CONSTRUÇÃO JURÍDICA, INTERAÇÕES ORGANIZACIONAIS E COOPERAÇÃO INTERNACIONAL

Bruno Amaral Machado e Priscilla Brito Silva Vieira

Desativismo judicial: a extradição Battisti no Supremo Tribunal Federal .505 Francisco Rezek e Israel Paulino

A decisão norte-americana do Caso Myriad: novos paradigmas para a Proteção patenTÁRIA DO CÓDIGO GENÉTICO HUMANO E BIOTECNOLOGIA 514 José Carlos Vaz e Dias e Clarisse De La Cerda 


\title{
Da desconsideração da personalidade jurídica nas relações consumeiristas brasileiras: análise à luz das teorias clássicas*
}

\author{
Disregard of legal personality in brazil's \\ consumer's relations: analysis in the light of \\ the classic theories
}

\author{
Daniel Amin Ferraz** \\ Marcus Vinicius Silveira de Sá***
}

\section{Resumo}

O presente trabalho visa rediscutir o instituto da desconsideração da personalidade jurídica no Brasil, previsto no Código de Defesa do Consumidor, com base nas teorias clássicas de levantamento da personalidade jurídica surgidas no âmbito do Direito Norte-Americano e Europeu, a fim de verificar se o instituto regulado pelo ordenamento jurídico nacional, aplicável às relações consumeristas, é coerente com aquele defendido pelas teorias clássicas, em especial no tocante aos seus limites e hipóteses de incidência.

Palavras-chave: Desconsideração da Personalidade Jurídica. Relação de Consumo. Sociedades Comerciais. Direito Empresarial. Limitação de Responsabilidade.

\begin{abstract}
The present work aims to re-discuss the disregard of legal personality in Brazil, as in the "Código de Defesa do Consumidor" ("Consumer's Protection Code"), based on the classic "lifting the corporate veil" theories, originated in the North-American and European Law, in order to verify if the institute regulated by the national legal system, incident in consumer's relations, is coherent with the one predicted by the classic theories, specially about its limits and cases of application.
\end{abstract}

* Autores convidados

** Mestre em Direito Empresarial, Univer-

Keywords: Disregard of legal entity. Consumer's Relations. Corporations. Corporate Law. Limited liability. sidade de Coimbra, Portugal; Doutor em Direito Empresarial Internacional, Universidad de València, Espanha; Pesquisador Convidado da OMC, Genebra (2004), Suiça; Professor do Mestrado/Doutorado em Direito e Políticas Públicas do UniCEUB, Brasília, DF; Advogado Titular de Amin, Ferraz, Coelho Advogados. 


\section{INTRODUÇÃO}

Desde seu surgimento, até os dias atuais, as sociedades comerciais ${ }^{1}$ vêm ganhando, cada vez mais, espaço no cenário econômico mundial, se'fato de a personificação das sociedades servir, inter alia, para a criação de centros autônomos de direitos e obrigações ${ }^{2}$.

Não obstante, a personificação, por si só, não exime os sócios de responderem pessoalmente por atos praticados pela sociedade empresária razão pela qual, na prática empresarial, a personificação das sociedades costuma vir acompanhada de outra característica das sociedades comerciais modernas: a limitação de responsabilidade.

Graças à conjugação destes dois elementos, mais pessoas passaram a reunir-se em sociedades visando explorar atividades econômicas no Mercado, pois, com eles, há redução dos riscos da atividade e dos custos de acesso ao capital, de agência e de monitoramento de outros sócios ${ }^{3}$.

Diante das vantagens decorrentes da união da limitação de responsabilidade com a personificação das sociedades, ocorreu uma verdadeira difusão das sociedades empresárias, de modo que foi possível verificar a expansão do número de sociedades constituídas e atuantes no Mercado.

Entretanto, não se pode ter como absolutos os elementos da personificação e da limitação de responsabi-

1 Cumpre referir que a atividade comercial sempre passou por um processo de evolução, e que gerou adaptabilidade do direito às necessidades do mercado. Assim, na origem a atividade mercantil sempre se organizou por intermédio da atuação do empresário individual, correspondendo a esta atividade o direito do comerciante individual. Com o incremento das relações mercantis no mercado, a atividade passou a ser desenvolvida pelos empresários coletivos, ou seja, pelas sociedades empresárias. Nesta fase surge o direito societário. Finalmente, as sociedades empresárias se organizam, cada dia com maior frequência, em grupos econômicos, passando o direito a regular a atuação destes potentados empresariais. Neste sentido, veja-se: FERRAZ, Daniel Amin. A concentração empresarial no contexto da economia internacional. In: FERRAZ, Daniel Amin. Direito empresarial: marco jurídico da internacionalização das empresas brasileiras. Curitiba: CRV, 2012. p. 9 e ss.

2 No Direito, a pessoa é, sempre, um centro de imputação de normas jurídicas. Desse modo, a personificação das sociedades tornalhe um centro de imputação de direitos e obrigações. Nesse sentido: CORDEIRO, António Menezes. O levantamento da personalidade colectiva no direito civil e comercial. Coimbra: Almedina, 2000. p.73.

3 TOMAZETTE, Marlon. Direito societário e globalização: rediscussão da lógica público-privada do direito societário diante das exigências de um mercado global. São Paulo: Atlas, 2014. lidade, tendo em vista a existência de diversos abusos que podem ser cometidos através da utilização indevida da personalidade jurídica. A possibilidade de atuação através da personalidade coletiva deve ter limites ${ }^{4}$.

Assim, e como resposta a chamada "crise da limitação de responsabilidade", surgiram as teorias da desconsideração da personalidade jurídica, desenvolvidas no âmbito do Direito Norte-Americano e Europeu.

No Brasil, o primeiro diploma legal a encarar, seriamente, o problema da desconsideração foi o Código de Defesa do Consumidor (CDC) em seu art. 28, o qual foi alvo de diversas críticas ao longo do seu trâmite no Congresso Nacional e continuou a ser questionado após sua promulgação em 11 de setembro de 1990.

Ao longo dos mais de 25 anos de introdução de fato do instituto no Brasil, doutrina e jurisprudência nacionais voltaram seus olhos principalmente para a construção e desenvolvimento das chamadas "teoria maior" e "teoria menor" da desconsideração, deixando de lado, por vezes, as teorias clássicas do instituto.

Assim, pretende-se reascender as discussões acerca dos problemas da desconsideração da personalidade jurídica no Brasil no tocante as relações consumeristas, ao analisar o art. 28 do Código de Defesa do Consumidor e as teorias nacionais da desconsideração, verificando-se sua (in)coerência com as teorias clássicas.

Para alcançar tais objetivos, o estudo em voga utilizará o método do levantamento bibliográfico, aprofundando-se as pesquisas no meio acadêmico por meio de artigos científicos, monografias, dissertações e teses publicadas nos diversos sítios eletrônicos das universidades brasileiras, europeias e americanas, bem como em outros sites e revistas especializadas. Será, ainda, analisada a icônica jurisprudência do Superior Tribunal de Justiça (STJ) sobre o tema, consubstanciada no julgamento do REsp 279.273/SP 6 .

Desta forma, verificar-se-á, inicialmente, a origem

4 FERRAZ, Daniel Amin. La concentración empresarial en el comercio internacional. Disponível em: <http://roderic.uv.es/ handle/10550/15234?show=full $>$. Acesso em: 01 jul. 2016.

5 Nesse sentido: FERRAZ, Daniel Amin. La concentración empresarial en el comercio internacional. Disponível em: <http://roderic. uv.es/handle/10550/15234? show=full > . Acesso em: 01 jul. 2016; e CORDEIRO, António Menezes. O levantamento da personalidade colectiva no direito civil e comercial. Coimbra: Almedina, 2000. p. 102.

6 BRASIL. Superior Tribunal de Justiça. REsp 279273/SP. Terceira Turma. Rel. Ministro Ari Pargendler. Rel. p/ Acórdão Ministra Nancy Andrighi. Brasília, 4 de dezembro de 2003. 
do instituto da desconsideração da personalidade jurídica no Direito Europeu e Norte-Americano e as teorias clássicas explicativas da desconsideração, quais sejam, as teorias subjetivas, objetivas, da aplicação das normas e negativista.

Após, será analisado o art. 28 do Código Brasileiro de Defesa do Consumidor e as teorias "maior" e "menor" da desconsideração da personalidade jurídica, desenvolvidas no Brasil para explicar a aplicação do instituto, inter alia, no Direito do Consumidor e Direito Ambiental.

Por fim, demonstrar-se-á a necessidade de reformulação do instituto do levantamento da personalidade coletiva nas relações consumeristas brasileiras, tal como previsto no art. $28, \$ 5^{\circ}$ do CDC, e o afastamento da "teoria menor", por estarem em total dissonância com as teorias clássicas e os objetivos primordiais da desconsideração da personalidade jurídica e resultarem em prejuízos à atividade empresarial e, consequentemente, ao desenvolvimento econômico nacional.

\section{A DESCONSIDERAÇão DA PERSONALIDADE JURÍDICA}

Antes de se aprofundar na doutrina da desconsideração da personalidade jurídica, destaca-se a existência de um problema terminológico ${ }^{7}$. No Direito Norte-Americano, utilizam-se os termos "disregard of legal entity" (desconsideração da entidade legal) ou simplesmente "disregard doctrine". No Direito Brasileiro e Português, utilizam-se as expressões "desconsideração da personalidade jurídica" e "levantamento da personalidade coletiva". No Direito Espanhol é conhecido como "doctrina del levantamiento del velo social" (doutrina do levantamento do véu social) e no Direito Alemão "Durchgriff bei juristischer Personen" (penetração nas pessoas jurídicas).

Existem ainda diversas outras denominações distintas para o mesmo instituto jurídico, o que por vezes causou confusão doutrinária ${ }^{8}$. Não obstante, tendo em vista se tratar do mesmo instituto, utilizar-se-á indistintamente tais expressões como sinônimas, dando-se pre-

7 CORDEIRO, António Menezes. O levantamento da personalidade colectiva no direito civil e comercial. Coimbra: Almedina, 2000. p. 102.

8 FERRAZ, Daniel Amin. La concentración empresarial en el comercio internacional. Disponível em: <http://roderic.uv.es/ handle/10550/15234?show=full $>$. Acesso em: 01 jul. 2016. ferência ao termo mais conhecido no Direito Brasileiro.

Destaca-se, ainda, o fato de que apesar de tecnicamente dizer respeito à personificação da sociedade, os impactos gerados pela aplicação da teoria da desconsideração dizer respeito, também, à limitação de responsabilidade, tendo em vista que permitirá expandi-la, estando a mesma a princípio limitada à pessoa coletiva, e havendo sua extensão (da responsabilidade) à pessoa dos sócios da sociedade?.

\subsection{A origem da disregard doctrine no direito norte-americano}

No Direito Americano, a desconsideração da personalidade jurídica teve origem em razões processuais e constitucionais ${ }^{10}$, tendo surgido da aplicação de regras de equidade que posteriormente foi levada para os tribunais. Assim, ao contrário da regra de que a Equidade segue o Direito, neste caso, o Direito seguiu a Equidade ${ }^{11}$.

A desconsideração da personalidade jurídica se apresenta como um instituto jurídico que surgiu para explicar as distintas soluções encontradas para os problemas derivados da personalidade coletiva ${ }^{12}$. Dentre os problemas mais básicos, destacam-se ${ }^{13}$ : (i) a confusão de esferas jurídicas; (ii) a subcapitalização; e (iii) prejuízos provocados a terceiros com abuso da personalidade jurídica.

Verifica-se a confusão de esferas jurídicas quando, devido à inobservância das regras de Direito Societário, não é clara a separação entre os patrimônios da sociedade e o patrimônio dos sócios.

Ocorre subcapitalização ${ }^{14}$ relevante para efeitos da

9 TOMAZETTE, Marlon. Direito societário e globalização: rediscussão da lógica público-privada do direito societário diante das exigências de um mercado global. São Paulo: Atlas, 2014. p. 136. 10 CORDEIRO, António Menezes. O levantamento da personalidade colectiva no direito civil e comercial. Coimbra: Almedina, 2000. p. 108.

11 SERICK, Rolf. Apariencia y realidad en las sociedades mercantiles: el abuso de derecho por medio de la persona jurídica. Barcelona: Ariel, 1958. p. 95-96.

12 FERRAZ, Daniel Amin. La concentración empresarial en el comercio internacional. Disponível em: <http://roderic.uv.es/ handle/10550/15234?show=full $>$. Acesso em: 01 jul. 2016.

13 Nesse sentido: CORDEIRO, António Menezes. O levantamento da personalidade colectiva no direito civil e comercial. Coimbra: Almedina, 2000. p. 118; FERRAZ, Daniel Amin. La concentración empresarial en el comercio internacional. Disponível em: <http://roderic.uv.es/ handle/10550/15234? show=full $>$. Acesso em: 01 jul. 2016.

14 Existem dois tipos distintos de subcapitalização: (i) subcapitalização nominal; e (ii) subcapitalização material. Na primeira, a sociedade tem um capital formalmente insuficiente para o objeto e atos a 
desconsideração sempre que uma sociedade tenha sido constituída com capital insuficiente, aferido em função de seu objeto ou de sua atuação.

Resta caracterizado o prejuízo a terceiros que justifique o levantamento da personalidade coletiva quando esta for usada, de modo ilícito ou abusivo, para prejudicar terceiros. Não basta, assim, o mero prejuízo. É necessário que o prejuízo a terceiros decorra "da utilização contrária a normas ou princípios gerais, incluindo a ética dos negócios”"15.

Em outras palavras, o abuso da personalidade jurídica consiste em uma "situação de abuso do direito ou de exercício inadmissível de posições jurídicas, verificada a proposito da actuação do visado, através da utilização de uma pessoa coletiva" ${ }^{\prime 16}$.

O comportamento que suscita o "levantamento do véu social" se caracteriza por atentar contra a legítima confiança existente entre as partes. O abuso da personalidade coletiva traduziria, em suma, a utilização das prerrogativas da personificação da sociedade em desrespeito ou descompasso com os objetivos que levaram a Lei em primeiro lugar a concedê-la ${ }^{17}$.

\subsection{Teorias clássicas explicativas da desconsideração}

Dentro das clássicas teorias explicativas da desconsideração da personalidade jurídica, destacam-se a teoria subjetiva, a teoria objetiva, a teoria da aplicação das normas, e a teoria negativista.

Analisar-se-á individualmente cada teoria.

\subsubsection{Teoria subjetiva}

Serick $^{18}$, analisando a jurisprudência dos tribunais

que se destina, podendo recorrer a capital alheio. Por outro lado, na segunda, constata-se uma efetiva insuficiência de fundos, seja próprio ou alheio. Para efeitos da desconsideração da personalidade jurídica, apenas esta última é, de fato, relevante, visto que não pode ser sanada. Nesse sentido: TOMAZETTE, Marlon. direito societário e globalização: rediscussão da lógica público-privada do direito societário diante das exigências de um mercado global. São Paulo: Atlas, 2014. 15 CORDEIRO, António Menezes. O levantamento da personalidade colectiva no direito civil e comercial. Coimbra: Almedina, 2000. p. 122.

16 CORDEIRO, António Menezes. O levantamento da personalidade colectiva no direito civil e comercial. Coimbra: Almedina, 2000. p. 123.

17 FERRAZ, Daniel Amin. La concentración empresarial en el comercio internacional. Disponível em: <http://roderic.uv.es/ handle/10550/15234? show=full $>$. Acesso em: 01 jul. 2016.

18 SERICK, Rolf. Apariencia y realidad en las sociedades mercantiles: norte-americanos, aponta cinco hipóteses em que originalmente permitiu-se a penetração da personalidade coletiva: (i) fraude a lei; (ii) fraude ao contrato; (iii) transmissão fraudulenta do patrimônio do devedor a uma pessoa jurídica em prejuízo de terceiro; (iv) nas relações entre matriz e filial em que, de forma desvirtuada, resta caracterizada situação de dependência de fato e de direito e esta for utilizada como mero instrumento por aquela para a promoção de atos abusivos; (v) atos praticados pela pessoa coletiva em contrariedade a boa-fé.

Ballantine $^{19}$ resume a aplicação da Teoria da Desconsideração para a hipótese em que o fato submetido a exame revela algum abuso derivado do privilégio da existência da personalidade jurídica.

Esta é a base da Teoria Subjetiva, segundo a qual

a autonomia da pessoa colectiva deveria ser afastada quando houvesse um abuso da sua forma jurídica, com vista para fins não permitidos. Na determinação dos tais 'fins' ou 'escopos', não permitidos, haveria que lidar com a situação objectiva e, ainda, com a intenção do próprio agente ${ }^{20}$.

A desconsideração exigira, portanto, um abuso consciente da personalidade coletiva ${ }^{21}$.

Dessa forma, a sociedade, por meio da atuação de seus administradores, pratica um determinado ato jurídico, mas é insolvente, não contando com patrimônio suficiente para quitar a obrigação. Em razão do princípio da autonomia societária e intangibilidade do capital social, o patrimônio dos sócios não poderia ser afetado pelas obrigações da sociedade, caso esta tenha sido constituída sobre a forma de um tipo societário com limitação de responsabilidade. Não fosse a Teoria da Desconsideração, os sócios evitariam assumir a responsabilidade pela inexecução ou pela execução defeituosa dos negócios jurídicos praticados pela sociedade ${ }^{22}$.

A Teoria Subjetiva surge, assim, "como um episódio natural da evolução da ideia de levantamento: jogam-se,

el abuso de derecho por medio de la persona jurídica. Barcelona: Ariel, 1958.

19 BALLANTINE, Henry Winthop. Ballantine on corporations. Chicago: Callaghan and Company, 1946.

20 CORDEIRO, António Menezes. O levantamento da personalidade colectiva no direito civil e comercial. Coimbra: Almedina, 2000. p. 125-126. 21 SERICK, Rolf apud CORDEIRO, António Menezes. O levantamento da personalidade colectiva no direito civil e comercial. Coimbra: Almedina, 2000. p. 125-126.

22 FERRAZ, Daniel Amin. La concentración empresarial en el comercio internacional. Disponível em: <http://roderic.uv.es/ handle/10550/15234? show=full>. Acesso em: 01 jul. 2016. 
tão só, os pressupostos da responsabilidade civil”23.

Vejamos, agora, a segunda teoria.

\subsubsection{Teoria objetiva}

A Teoria Objetiva é resultado da rejeição de elementos subjetivos para se proceder à desconsideração da personalidade jurídica. Seria uma evolução comum aos instrumentos jurídicos que visam à sindicância do sistema sobre as soluções jurídicas ${ }^{24}$. Em uma primeira fase, faz-se tudo depender das intenções do agente, mas uma vez conquistado o instituto, este é objetivado e passa a depender, unicamente, das ações em contrariedade ao ordenamento.

Uma vez abandonada a intenção do agente, faz-se necessário a ponderação dos institutos em jogo para se proceder a desconsideração. Levantar-se-ia a personalidade coletiva quando tais institutos fossem afastados pela invocação da personalidade jurídica contra a intencionalidade normativa ${ }^{25}$.

Por meio da aplicação da Teoria Objetiva, a desconsideração deixa de ser vista como pena/sanção àqueles que visam manipular o ordenamento jurídico e através da personificação da sociedade e passa a ser interpretada como mera consequência do não cumprimento de uma norma legal.

Estariam qualificados dentro da teoria objetiva os casos de concentração empresarial. Afetada a responsabilidade das partes, em razão da não aplicação da intangibilidade do capital social e da vinculação patrimonial dos entes do grupo, aplicar-se-ia a teoria da desconsideração e o patrimônio de todo o grupo responderia pelas obrigações assumidas ${ }^{26}$. Em suma, a mera existência de concentração empresarial seria motivo suficiente para a aplicação do levantamento da personalidade coletiva.

\subsubsection{Teoria da aplicașão das normas}

Apresentada, inicialmente, por Müller-Freienfels como alternativa a Teoria subjetiva de Serick, a Teoria

23 CORDEIRO, António Menezes. O levantamento da personalidade colectiva no direito civil e comercial. Coimbra: Almedina, 2000. p. 126. 24 CORDEIRO, António Menezes. O levantamento da personalidade colectiva no direito civil e comercial. Coimbra: Almedina, 2000. p. 127.

25 FERRAZ, Daniel Amin. La concentración empresarial en el comercio internacional. Disponível em: <http://roderic.uv.es/ handle/10550/15234? show=full $>$. Acesso em: 01 jul. 2016.

26 FERRAZ, Daniel Amin. La concentración empresarial en el comercio internacional. Disponível em: <http://roderic.uv.es/ handle/10550/15234?show=full $>$. Acesso em: 01 jul. 2016. da Aplicação das normas defende que a desconsideração não traduziria, propriamente, um problema geral da personalidade coletiva, mas uma questão de aplicação das distintas normas jurídicas.

Quando as normas tivessem "uma pretensão de aplicação absoluta ou visassem atingir a realidade subjacente à própria personalidade jurídica, aplicar-se-iam"27. O "detrimento" das regras inerentes à personificação das sociedades seria, destarte, mera decorrência da aplicação de normas com tais objetivos.

Assim, tem-se que a aplicação da Teoria das Normas é, a rigor, objetiva, razão pela qual coaduna-se com o entendimento de que tal teoria nada mais é senão uma subespécie da Teoria Objetiva apresentada anteriormente $e^{28}$.

\subsubsection{Teoria Negativista}

A Teoria Negativista defendida e propagada, principalmente, por Wilhelm, nega a autonomia à desconsideração da personalidade jurídica, pois lidaria com proposições vagas e conduziria a insegurança jurídica, razão pela qual haveria de se determinar expressamente os deveres concretos que incidam sobre os membros da pessoa coletiva, de modo que, no limite da teoria, apenas seria possível responsabilizar os dirigentes ou administradores das sociedades por falta de diligência ${ }^{29}$.

A desconsideração da personalidade jurídica, independentemente da teoria explicativa adotada, decerto conquistou sua posição nos mais diversos ordenamentos jurídicos.

Trata-se, porém, de medida excepcionalíssima. A regra deve permanecer privilegiando a manutenção da autonomia societária consubstanciada na personificação da sociedade, e a limitação de responsabilidade. Apenas nos casos em que comprovado o abuso da personalidade jurídica ou verificado confusão patrimonial poderia ser justificado a desconsideração da personalidade, visando alcançar o patrimônio dos sócios.

27 CORDEIRO, António Menezes. O levantamento da personalidade colectiva no direito civil e comercial. Coimbra: Almedina, 2000. p.129.

28 FERRAZ, Daniel Amin. La concentración empresarial en el comercio internacional. Disponível em: <http://roderic.uv.es/ handle/10550/15234? show=full $>$. Acesso em: 01 jul. 2016.

29 WILHEIM, Jan. apud CORDEIRO, António Menezes. O levantamento da personalidade colectiva no direito civil e comercial. Coimbra: Almedina, 2000. p. 130. 
Apresentado o instituto da desconsideração da personalidade jurídica e suas teorias clássicas, passa-se, agora, à análise do ordenamento jurídico nacional no tocante a previsão constante no Código de Defesa do Consumidor e as teorias desenvolvidas pela doutrina nacional, aplicadas pela jurisprudência dos Tribunais Pátrios.

\section{A DESCONSIDERAÇÃo NAS RELAÇões CONSUMERISTAS BRASILEIRAS}

Apesar das resistências, a positivação da desconsideração da personalidade jurídica já vinha ocorrendo, ainda que timidamente ${ }^{30}$, por meio de legislação específica desde 1940, através do art. $121^{31}$ da Antiga Lei das Sociedades Anônimas ${ }^{32 / 33}$, e posteriormente, a partir de 1966, com base no art. $135^{34}$ do Código Tributário Nacional $^{35}$.

Não obstante, foi o Código de Defesa do Consumidor o primeiro diploma legal a tratar seriamente da questão do levantamento da personalidade coletiva, determinando suas hipóteses de aplicação, claro que limitada às relações consumeristas.

30 GRINOVER, Ada Pellegrini et al. Código brasileiro de defesa do consumidor: comentado pelos autores do anteprojeto. 6. ed. Rio de Janeiro: Forense Universitária, 2000. p. 204-206.

31 Art. 121. Os diretores não são pessoalmente responsáveis pelas obrigações que contraírem em nome da sociedade e em virtude de ato regular de gestão. $\ 1^{\circ}$ Respondem, porém, civilmente, pelos prejuízos que causarem, quando procederem: I, dentro de suas atribuições ou poderes, com culpa ou dolo; II, com violação da lei ou dos estatutos.

32 BRASIL. Decreto-Lei n. 2.627 de 26 de setembro de 1940. Dispõe sobre as sociedades por ações. Disponível em: <http://www.planalto.gov.br/ccivil_03/decreto-lei/Del2627.htm>. Acesso em: 05 jul. 2016.

33 Em 1976, com o advento da Lei n. 6.404, revogou-se parcialmente a Antiga Lei das S.A., com exceção do que disposto nos arts. 59 a 73, de modo que, atualmente, o que disposto no antigo art. 121 está regulado no art. 158 da Lei das Sociedade Anônimas.

34 Art. 135. São pessoalmente responsáveis pelos créditos correspondentes a obrigações tributárias resultantes de atos praticados com excesso de poderes ou infração de lei, contrato social ou estatutos: I - as pessoas referidas no artigo anterior; II - os mandatários, prepostos e empregados; III - os diretores, gerentes ou representantes de pessoas jurídicas de direito privado.

35 BRASIL. Lei n. 5.172 de 25 de outubro de 1966. Dispõe sobre o Sistema Tributário Nacional e institui normas gerais de direito tributário aplicáveis à União, Estados e Municípios. Disponível em: <http://www.planalto.gov.br/ccivil_03/leis/L5172Compilado. htm>. Acesso em: 05 jul. 2016.
Após a entrada em vigor do CDC, a doutrina nacional ocupou-se de formular teorias para explicar e justificar a aplicação da desconsideração da personalidade jurídica no Brasil, as quais serão exploradas após analisarmos o disposto no art. 28 do Código de Defesa do Consumidor.

\subsection{A desconsideração no art. 28 do CDC}

O artigo 28 do Código Brasileiro de Defesa do Consumidor seguiu a tendência do Civil Law de normatizar o instituto da desconsideração de personalidade jurídica e o introduziu ao ordenamento jurídico Brasileiro.

Com efeito, eis o inteiro teor do art. 28 do CDC:

Art. 28. O juiz poderá desconsiderar a personalidade jurídica da sociedade quando, em detrimento do consumidor, houver abuso de direito, excesso de poder, infração da lei, fato ou ato ilícito ou violação dos estatutos ou contrato social. A desconsideração também será efetivada quando houver falência, estado de insolvência, encerramento ou inatividade da pessoa jurídica provocados por má administração. $\$ 1^{\circ}$ (Vetado).

\2 $2^{\circ}$ As sociedades integrantes dos grupos societários e as sociedades controladas, são subsidiariamente responsáveis pelas obrigações decorrentes deste código.

$\$ 3^{\circ}$ As sociedades consorciadas são solidariamente responsáveis pelas obrigações decorrentes deste código.

$\$ 4^{\circ}$ As sociedades coligadas só responderão por culpa.

$\int 5^{\circ}$ Também poderá ser desconsiderada a pessoa jurídica sempre que sua personalidade for, de alguma forma, obstáculo ao ressarcimento de prejuízos causados aos consumidores.

A primeira parte do caput do artigo traz uma série de critérios subjetivos de levantamento da personalidade coletiva, mantendo a tradição já presente em nosso ordenamento jurídico e seguindo a clássica doutrina da desconsideração.

Na segunda parte, entretanto, parcela da doutrina defende ter ocorrido uma verdadeira inovação ${ }^{36}$, ao incluir critérios objetivos como a falência e a inatividade da pessoa jurídica. Diz-se que "é a primeira vez que o Direito legislado acolhe a teoria da desconsideração sem levar em conta

36 GRINOVER, Ada Pellegrini et al. Código brasileiro de defesa do consumidor: comentado pelos autores do anteprojeto. 6. ed. Rio de Janeiro: Forense Universitária, 2000. p. 208. 
a configuração da fraude ou do abuso de direito',37. Em suma, argumenta-se que, com a inclusão dessas hipóteses, o ordenamento jurídico nacional passou a prever situações em que, independentemente de abuso ou fraude, poder-se-ia promover a desconsideração da personalidade jurídica e responsabilizar os sócios através da aplicação da teoria objetiva.

Entretanto, imperioso destacar não ser este o posicionamento mais correto. Explica-se.

Em que pese o fato de a decretação da falência ou a constatação de estado de insolvência ou encerramento ou inatividade da pessoa jurídica serem fatores auferíveis objetivamente, ou seja, sem a necessidade de abuso ou fraude, não há de se falar em aplicação da teoria objetiva no caso concreto, pois a parte final do dispositivo limita a aplicação da desconsideração à configuração de má-administração. Em outras palavras, o legislador condicionou a desconsideração naqueles casos a um critério subjetivo: a má-administração.

Desta forma, a falência, o estado de insolvência e/ ou o encerramento ou inatividade da pessoa jurídica por si só não são capazes de permitir a aplicação, nas relações consumeristas, da desconsideração da personalidade jurídica, pois se exige que qualquer um daqueles seja derivado de má-administração para tanto. Poderia se afirmar, portanto, ter ocorrido uma espécie de "subjetivação" de critérios objetivos, não havendo que se falar, nestes casos, da aplicação da teoria objetiva, mas sim na aplicação da teoria subjetiva.

Por outro lado, parte da doutrina entende que os $\int \varsigma 2^{\circ}, 3^{\circ}$ e $4^{\circ}$, apesar de presentes no artigo sobre desconsideração da personalidade jurídica, tratam da responsabilidade dos grupos de sociedades. Ademais, têm-se o entendimento de que tais dispositivos estariam eivados de vício de pertinência, por tratarem da responsabilidade dos grupos e não da desconsideração da personalidade jurídica ${ }^{38}$.

Discorda-se de tal entendimento. Isso porque, como demonstrado alhures, a concentração empresarial é o elemento caracterizador do critério objetivo da descon-

37 GRINOVER, Ada Pellegrini et al. Código brasileiro de defesa do consumidor: comentado pelos autores do anteprojeto. 6. ed. Rio de Janeiro: Forense Universitária, 2000. p. 208.

38 GRINOVER, Ada Pellegrini et al. Código brasileiro de defesa do consumidor: comentado pelos autores do anteprojeto. 6. ed. Rio de Janeiro: Forense Universitária, 2000. p.204-206. sideração ${ }^{39}$.

Ademais, apesar de o veto presidencial ter recaído sobre o $\$ 1^{\circ}$, é o $\$ 5^{\circ}$ do art. 28 que, desde o início, gerou maiores discussões doutrinárias, especialmente após a divulgação das razões do veto ${ }^{40}$, pois de seu inteiro teor verifica-se que estaria direcionado a esse último e não aquele primeiro.

Não obstante, as demais discussões sobre o dispositivo giram entorno principalmente do caráter absolutista e genérico da norma, que, utilizando-se de expressões vagas e sem trazer qualquer tipo de delimitação ou restrição, permite a desconsideração da personalidade jurídica em qualquer hipótese.

A previsão ampla deixa clara opção legislativa pela proteção ao consumidor ${ }^{41}$. Pela ponderação entre os interesses de satisfação do crédito do consumidor e da continuidade do exercício da atividade empresarial, o legislador brasileiro garantiu máxima proteção daquele em detrimento desse.

\subsection{As teorias brasileiras "maior"e "menor" da desconsideração}

Em tese, parecer ser que no Brasil conviveriam duas "teorias" da desconsideração da personalidade jurídica: uma denominada de teoria maior e outra de teoria menor, a qual tem sido aceita, ainda que por vezes parcialmente, pela maioria da doutrina e jurisprudência nacional ${ }^{42}$.

A primeira seria o resultado da análise dos trabalhos de Rolf Serick (teoria subjetiva) por Rubens Requião em

39 Ver: FERRAZ, Daniel Amin. O grupo de sociedades: mecanismo de inserção da empresa transnacional na nova ordem econômica mundial. Revista de Direito Internacional, Brasília, v.9, n.1. p.15-25, jan./ jun. 2012.

40 Segundo a Mensagem no 664 da Presidência da República ao Presidente do Senado, que comunicou o veto parcial ao Projeto de Lei no $97 / 89$ (n 3.683/89 na Câmara dos Deputados), o parágrafo primeiro do art. 28 foi vetado, visto que "o caput do art. 28 já contém todos os elementos necessários à aplicaşão da desconsideração da personalidade jurídica, que constitui, conforme doutrina amplamente dominante no direito pátrio e alienigena, técnica excepcional de repressão a práticas abusivas". Tal mensagem está disponível pra consulta em: <http://www.planalto.gov. br/ccivil_03/leis/Mensagem_Veto/anterior_98/vep664-L8078-90. htm>. Acesso em: 29 jun. 2016.

41 MARQUES, Claudia Lima; BENJAMIN, Antônio Herman V.; MIRAGEM, Bruno. Comentários ao código de defesa do consumidor. 2. ed. São Paulo: Revista dos Tribunais, 2006.

42 COELHO, Fabio Ulhoa. A teoria maior e a teoria menor da desconsideração. Revista de Direito Bancário e do Mercado de Capitais, v. 17, n. 65, p. 21-30, jul./set. 2014. 
1960, que buscou defender a aplicabilidade da disregard doctrine em âmbito nacional, ainda que sem previsão legislativa específica para tanto, sempre que verificada fraude contra credores ou abuso de direito por meio da personalidade jurídica ${ }^{43}$.

Por sua vez, segundo a "Teoria Menor", bastaria o não pagamento de um crédito para que se promovesse a desconsideração da personalidade jurídica ${ }^{44}$. Caso a sociedade não possuísse patrimônio suficiente para quitar com as obrigações, mas seus sócios fossem solventes, isso bastaria para desconsiderar a personalidade coletiva e responsabilizá-los perante o credor $^{45}$.

No âmbito do Superior Tribunal de Justiça, a questão da desconsideração da personalidade jurídica e suas teorias foram amplamente debatidas no julgamento do REsp 279.273/SP ${ }^{46}$, em que a controvérsia se instaurou acerca das hipóteses de cabimento do instituto.

A tese que prevaleceu naquele julgado foi a defendida pela Ministra Nancy Andrighi, designada relatora para o acórdão, e pode ser facilmente extraída do seguinte trecho da ementa:

\begin{abstract}
A teoria maior da desconsideração, regra geral no sistema jurídico brasileiro, não pode ser aplicada com a mera demonstração de estar a pessoa jurídica insolvente para o cumprimento de suas obrigações. Exige-se, aqui, para além da prova de insolvência, ou a demonstração de desvio de finalidade (teoria subjetiva da desconsideração), ou a demonstração de confusão patrimonial (teoria objetiva da desconsideração).
\end{abstract}

A teoria menor da desconsideração, acolhida em nosso ordenamento jurídico excepcionalmente no Direito do Consumidor e no Direito Ambiental, incide com a mera prova de insolvência da pessoa jurídica para o pagamento de suas obrigações, independentemente da existência de desvio de finalidade ou de confusão patrimonial.

Para a teoria menor, o risco empresarial normal às atividades econômicas não pode ser suportado pelo terceiro que contratou com a pessoa jurídica, mas pelos sócios e/ou administradores desta, ainda que

43 REQUIÃO, Rubens. Curso de direito comercial. São Paulo: Saraiva, 1998. V. 1.

44 TOMAZETTE, Marlon. Direito societário e globalização: rediscussão da lógica público-privada do direito societário diante das exigências de um mercado global. São Paulo: Atlas, 2014.

45 COELHO, Fabio Ulhoa. A teoria maior e a teoria menor da desconsideração. Revista de Direito Bancário e do Mercado de Capitais, v. 17, n. 65, p. 21-30, jul./set. 2014.

46 BRASIL. Superior Tribunal de Justiça. REsp 279273/SP. Terceira Turma. Rel. Ministro Ari Pargendler. Rel. p/ Acórdão Ministra Nancy Andrighi. Brasília, 4 de dezembro de 2003. estes demonstrem conduta administrativa proba, isto é, mesmo que não exista qualquer prova capaz de identificar conduta culposa ou dolosa por parte dos sócios e/ou administradores da pessoa jurídica.

A aplicação da teoria menor da desconsideração às relações de consumo está calcada na exegese autônoma do $\int 5^{\circ}$ do art. 28 , do CDC, porquanto a incidência desse dispositivo não se subordina à demonstração dos requisitos previstos no caput do artigo indicado, mas apenas à prova de causar, a mera existência da pessoa jurídica, obstáculo ao ressarcimento de prejuízos causados aos consumidores.

Segundo esse entendimento, replicado desde então nos demais julgados do STJ e adotado por todas as instâncias dos Tribunais Pátrios, o $\$ 5^{\circ}$ do art. 28 do CDC possui aplicabilidade autônoma. Desse modo, não seria necessária a verificação de qualquer das hipóteses de desconsideração previstas no caput daquele artigo para proceder à desconsideração da personalidade jurídica no caso concreto, bastando, como já mencionado, o não pagamento de um crédito amparado pelo Direito do Consumidor.

\section{Considerações finais}

Da necessária reformulação da desconsideração da personalidade jurídica nas relações consumeristas brasileiras

A personificação da pessoa coletiva e a limitação de responsabilidade foram responsáveis pela difusão das sociedades comerciais modernas, mas o desvirtuamento de seus propósitos é capaz de gerar danos e prejuízos a terceiros, tendo sido necessário impor limites à proteção à personalidade jurídica e à autonomia societária, por vezes relativizando-as.

Em casos excepcionais, o Direito permite a desconsideração da personalidade jurídica e para justificar a aplicação do instituto surgiram as teorias explicativas clássicas, das quais prevaleceram as teorias subjetiva e objetiva.

No Brasil, inicialmente, observou-se, atentamente, a Teoria Subjetiva de Serick com a introdução do instituto por Rubens Requião, cuja doutrina deu origem a posteriormente denominada "teoria maior da desconsideração”. Assim, tal teoria observava, a princípio, a teoria subjetiva clássica. 
Não obstante, posteriormente, passou-se a prever e defender que a simples verificação da existência de confusão patrimonial entre a sociedade e seu(s) sócio(s), também, permitiria a desconsideração da personalidade jurídica, de modo que dizem terem sido adotados, também, critérios da teoria objetiva.

Entretanto, mister destacar a existência de conflito doutrinário nesse ponto, pois apesar de alguns defenderem que a confusão patrimonial é "requisito primordial" ${ }^{47}$ da desconsideração, outros posicionam-se no sentido de que a confusão patrimonial é apenas um indício que pode servir de meio de prova para se promover a desconsideração ${ }^{48}$, mas nunca seu fundamento.

Acredita-se ser este o entendimento mais correto, porquanto, na prática, existem situações em que o patrimônio da sociedade e o do sócio podem confundir-se durante o desempenho da atividade prevista no Ato Constitutivo independentemente da ocorrência de atos ilícitos ou abusivos ${ }^{49}$, ou, ainda, decorrer de uma necessidade da atividade desenvolvida ${ }^{50}$.

Analisando-se, atentamente, o sistema jurídico nacional, têm-se que a finalidade do levantamento da personalidade coletiva foi de certo modo desvirtuada ao se abranger ao máximo suas hipóteses de incidência nas relações consumeristas por meio do disposto no art. 28, $\$ 5^{\circ}$ do Código de Defesa do Consumidor e com o desenvolvimento da chamada "teoria menor" da desconsideração.

$\mathrm{O} \$ 5^{\circ}$ do art. 28 do CDC não encontra qualquer amparo teórico quando confrontado com as teorias clássicas. Não se exige abuso ou má-fé, tampouco prevê uma hipótese concreta para a aplicação objetiva do instituto. O dispositivo, como dito, pretende tornar absoluta a proteção dos créditos consumeristas e permite a desconsideração da personalidade jurídica irrestritamente.

Tal opção, supostamente, estaria justificada na hipossuficiência do consumidor perante as grandes socie-

47 COMPARATO, Fábio Konder; SALOMÃO FILHO, Calixto. O poder de controle na sociedade anônima. 4. ed. Rio de Janeiro: Forense, 2005. p. 450.

48 LEHMANN, Michael; FRANCESCHELLI, Vicenzo apud TOMAZETTE, Marlon. Curso de direito empresarial: teoria geral e direito societário. São Paulo: Atlas, 2012. p. 237. v. 1.

49 LINS, Daniela Storry. Aspectos polêmicos atuais da desconsideração da personalidade jurídica no código de defesa do consumidor e a lei antitruste. Rio de Janeiro: Lumen Juris, 2002. p. 39.

50 TOMAZETTE, Marlon. Curso de direito empresarial: teoria geral e direito societário. São Paulo: Atlas, 2012. p. 237. v. 1. dades comerciais, mas da forma em que foi elaborada acaba por tornar regra o que deve ser tratado como exceção. Afinal, a personalidade jurídica, quando aliada a responsabilidade limitada, sempre será de alguma forma obstáculo ao ressarcimento do consumidor, porquanto impede que este alcance, diretamente, o patrimônio dos sócios para satisfazer seu crédito.

Conforme crítica manifestada há mais de 20 anos, a interpretação literal do dispositivo implicaria a seguinte situação analógica: "se causares prejuízo com abuso irás preso; também irás preso se causares prejuízo por má administração; e também irás preso sempre que, de qualquer forma, causares prejuízo" 51 .

Apesar de hiperbólica, a crítica ainda é valida e destaca importância de se proceder a interpretação lógica e teleológica do dispositivo antes de aplicá-lo ao caso concreto, sob pena de se desvirtuar completamente o instituto da desconsideração da personalidade jurídica.

Com efeito, tem-se que a "Teoria Menor da Desconsideração" também não encontra equivalência ou amparo nas teorias explicativas clássicas.

A “teoria menor" não se preocupa em verificar no caso concreto se houve ou não abuso da personalidade jurídica, tampouco a ocorrência de alguma das hipóteses para a aplicação nos termos da Teoria Objetiva do instituto; ao contrário, é fruto de uma inovação legislativo-jurisprudencial brasileira que não parecer ter se preocupado em observar atentamente as considerações da clássica doutrina Norte-Americana e Europeia sobre a matéria.

Ao contrário do objetivo clássico do instituto da desconsideração, de proteger a existência da autonomia patrimonial evitando-se o enriquecimento ilícito dos sócios em detrimento dos credores da sociedade, a teoria menor acaba por eliminá-la e ignorar a limitação de responsabilidade no âmbito do Direito do Consumidor, através da aplicação do instituto da desconsideração da personalidade jurídica sempre que constatado o não pagamento de um crédito consumerista.

Em que pese a importância da proteção ao crédito, sobretudo daquele cujo titular é legalmente considerado como hipossuficiente diante da sociedade empresária, como no caso do consumidor, este não pode ser ab-

51 AMARO, Luciano. Desconsideração da pessoa jurídica no código de defesa do consumidor. Revista de Direito do Consumidor, São Paulo, n. 5, jan./mar. 1993. p. 178. 
solutizado ao ponto de dar fim à limitação de responsabilidade e à autonomia patrimonial das sociedades, postulados básicos da realização dos grandes negócios empresariais, porquanto os custos sociais de tal medida se sobrepõem, em muito, aos benefícios adquiridos individualmente pelo consumidor credor da sociedade.

Os custos da eliminação desses elementos essenciais às sociedades comerciais modernas são os mesmos da "ilimitação" de responsabilidade, trazendo a tona os ris$\cos \mathrm{da}$ atividade e aumentando, inter alia, os custos de acesso ao capital, de agência e de monitoramento de outros sócios.

Ademais, tal eliminação inviabiliza o desenvolvimento das atividades economicamente relevantes capazes de gerar incontáveis benefícios à sociedade. Assim, não há dúvida de que o progresso e desenvolvimento econômico por elas proporcionado são mais importantes que a mera satisfação individual de um credor.

Dessa forma, não há dúvida de que o $\$ 5^{\circ}$ do art. 28 do CDC e a "teoria menor da desconsideração" estão em completa dissonância com as teorias clássicas do levantamento da personalidade coletiva, necessitando de profunda reformulação e/ou completo abandono. Importante é a função da doutrina e jurisprudência nessa trajetória, que deve voltar seus olhos às origens da desconsideração da personalidade jurídica e suas teorias clássicas, a fim de permitir a reconstrução do instituto no Direito Brasileiro.

\section{REFERÊNCIAS BIBLIOGRÁFICAS}

AMARO, Luciano. Desconsideração da pessoa jurídica no código de defesa do consumidor. Revista de Direito do Consumidor, São Paulo, n. 5, jan./mar. 1993.

ANDRIGHI, Fátima Nancy. Desconsideração da personalidade jurídica. Disponível em: <www.mprs.mp.br/areas/ consumidor/arquivos/desconsideracao.pdf $>$. Acesso em: 30 jun. 2016.

ANTUNES, José Engrácia. Estrutura e responsabilidade da empresa: o moderno paradoxo regulatório. Disponível em: <http://direitosp.fgv.br/sites/direitosp.fgv.br/files/rdgv_02_p029_068.pdf>. Acesso em: 20 jun. 2016.

BALLANTINE, Henry Winthop. Ballantine on corporations. Chicago: Callaghan and Company, 1946.
BLUMBERG, Phillip I. The multinational challenge to corporation law: the search for a new corporate personality. New York: Oxford, 2003.

BRASIL. Decreto-Lei n. 2.627 de 26 de setembro de 1940. Dispõe sobre as sociedades por ações. Disponível em: <http://www.planalto.gov.br/ccivil_03/decreto-lei/ Del2627.htm>. Acesso em: 05 jul. 2016.

BRASIL. Lei n. 5.172 de 25 de outubro de 1966. Dispõe sobre o Sistema Tributário Nacional e institui normas gerais de direito tributário aplicáveis à União, Estados e Municípios. Disponível em: < http://www.planalto.gov. br/ccivil_03/leis/L5172Compilado.htm>. Acesso em: 05 jul. 2016.

BRASIL. Lei n. 6.404 de 15 de setembro de 1976. Dispõe sobre as Sociedades por Ações. Disponível em: < http:/ / www.planalto.gov.br/ccivil_03/LEIS/L6404consol. htm>. Acesso em: 01 jul. 2016.

BRASIL. Lei n. 8.078 de 11 de setembro de 1990. Dispõe sobre a proteção do consumidor e dá outras providências. Disponível em: < http://www.planalto.gov.br/ccivil_03/leis/L8078.htm>. Acesso em: 01 jul 2016.

BROSETA PONT, Manuel. Manual de derecho mercantil. 10. ed. Madrid: Tecnos, 2000.

COELHO, Fabio Ulhoa. A teoria maior e a teoria menor da desconsideração. Revista de Direito Bancário e do Mercado de Capitais, v. 17, n. 65, jul./set. 2014.

COELHO, Fabio Ulhoa. Curso de direito comercial: direito de empresa. São Paulo: Saraiva, 2014. V. 2.

COLLINGS, Hugh. Ascription of legal responsibility to groups in complex patterns of economic integration. Disponível em: < http://onlinelibrary.wiley.com/ doi/10.1111/j.1468-2230.1990.tb01838.x/abstract;jses sionid $=543 \mathrm{~EB} 448 \mathrm{E} 67 \mathrm{D} 49 \mathrm{D} 71 \mathrm{BECBFC1A7866DAD}$. f02t01>. Acesso em: 28 jun. 2016.

COMPARATO, Fábio Konder; SALOMÃO FILHO, Calixto. O poder de controle na sociedade anônima. 4. ed. Rio de Janeiro: Forense, 2005.

CORDEIRO, António Menezes. O levantamento da personalidade colectiva no direito civil e comercial. Coimbra: Almedina, 2000.

FERRAZ, Daniel Amin. Grupo de sociedades: instrumento jurídico de organização da empresa plurissocietária. Revista de Direito Internacional, Brasília, v. 12, n. 2, p. 494-510, 2014. 
FERRAZ, Daniel Amin. O grupo de sociedades: mecanismo de inserção da empresa transnacional na nova ordem econômica mundial. Revista de Direito Internacional, Brasília, v. 9, n. 1. p. 15-25, jan./jun. 2012.

FERRAZ, Daniel Amin. La concentración empresarial en el comercio internacion Disponível em: <http://roderic.uv.es $/$ handle $/ 10550 / 15234$ ? show $=$ full $>$. Acesso em: 01 jul. 2016.

FERRAZ, Daniel Amin. A concentração empresarial no contexto da economia internacional. In:

Direito empresarial: marco jurídico da internacionalização das empresas brasileiras. Curitiba: Curitiba, 2012.

GRINOVER, Ada Pellegrini et al. Código brasileiro de defesa do consumidor: comentado pelos autores do anteprojeto. 6. ed. Rio de Janeiro: Forense Universitária, 2000.

HANSMANN, Henry; KRAAKMAN, Reinier. The end of history for corporate law. Disponível em: <http:// www.law.harvard.edu/programs/olin_>. Acesso em: 30 jun. 2016.

HANSMANN, Henry; KRAAKMAN, Reinier. What is corporate law? In: KRAAKMAN, Reinier et al. The anatomy of corporate law: a comparative and functional approach. New York: Oxford University Press, 2004.
LINS, Daniela Storry. Aspectos polêmicos atuais da desconsideração da personalidade juridical no código de defesa do consumidor e lei antitruste. Rio de Janeiro: Lumen Juris, 2002.

MARQUES, Claudia Lima; BENJAMIN, Antônio Herman V.; MIRAGEM, Bruno. Comentários ao código de defesa do consumidor. 2. ed. São Paulo: Revista dos Tribunais, 2006.

MICKELTHWAIT, John; WOOLDRIDGE, Adrian. The company: a short history of a revolutionary idea. New York: A modern Library, 2005.

REQUIÃO, Rubens. Curso de direito comercial. São Paulo: Saraiva, 1998. v. 1.

SERICK, Rolf. Apariencia y realidad en las sociedades mercantiles: el abuso de derecho por medio de la persona jurídica. Barcelona: Ariel, 1958.

TOMAZETTE, Marlon. Curso de direito empresarial: teoria geral e direito societário. São Paulo: Atlas, 2012. v. 1.

TOMAZETTE, Marlon. Direito societário e globalização: rediscussão da lógica público-privada do direito societário diante das exigências de um mercado global. São Paulo: Atlas, 2014. 
Para publicar na Revista de Direito Internacional, acesse o endereço eletrônico www.rdi.uniceub.br ou www.brazilianjournal.org.

Observe as normas de publicação, para facilitar e agilizar o trabalho de edição. 